\title{
Overcoming psychological barriers in discourse interaction in the era of information
}

\author{
Ekaterina Bobyreva $^{1^{*}}$, Marina Zheltukhina ${ }^{2}$, Mariana Busygina $^{3}$ and Olga Khudobina ${ }^{4,}$ \\ ${ }^{1}$ Volgograd State Socio-Pedagogical University, Volgograd, Russia, new_life@mail.ru \\ ${ }^{2}$ Volgograd State Socio-Pedagogical University, Volgograd, Russia, zzmr@mail.ru \\ ${ }^{3}$ Volgograd State Socio-Pedagogical University, Volgograd, Russia, busygina_maryana@mail.ru \\ ${ }^{4}$ Ugra State University, Humanitarian Institute of Nothern Studies, olga_hdb@-mail.ru
}

\begin{abstract}
The article deals with the types of communicative competence in different types of discourse. Communicative competence refers to the ability to predict a communicative situation in a specific area of communication which becomes important in the era of information, to manage the process of communication in a certain situational environment. Levels of language personality formation are distinguished. The concept of a psychological barrier arising in the process of communication is given. Psychological barrier refers to a condition that impedes full development and manifestation of a personality. Multilevel character of communicative competence is shown, levels of its formation are distinguished; such types as lexical, textual and discourse competence are considered. As a person enters discourse space and develops communicative competence, his emotional state changes - from negative or neutral emotions to positive emotions. The question is raised about the possibility of communicative failures caused by communication barriers arising during communication. Types of communicative barriers, their characteristics and ways to overcome them are considered; besides, barriers related to insufficient proficiency in a particular level of language (phonetic, lexical, stylistic) are considered. Among the reasons for communicative barriers are: features of communicants' intelligence; difference in interpreting concepts; difference in vocabulary; misunderstanding of communicative situation; psychological characteristics of partners; social, political, professional, religious differences.Many of these barriers appear in modern society which overcomes specific changes in the era of information. Significance of psychological factor as well as level of formation of emotional competence to overcome emerging communicative barriers is shown.
\end{abstract}

\section{Introduction}

In the process of communication in different types of discourse, there "may arise states that impede full manifestation of the personality, block its activity, such states may be realized both in the intellectual and practical sphere, impede creative expression, lead to general dissatisfaction with the learning process and reduce the effectiveness of professional training" [1]. Such conditions can be called forth by the psychological barriers - obstacles and difficulties that arise in the process of communication in almost any type of discourse. Problem of perception, understanding and interpretation of the received information is one of the main problems of modern society in general [2].

\section{Problem Statement}

In many respects psychological barriers are the result of the contradiction between new communicative tasks and opportunities that a discourse participant has, which imply a good level of knowledge of the subject sphere of communication, general level of knowledge and motivated emotional communicative activity in the process of social interaction [3]. Problem of overcoming communicative barriers appears to be relevant because such barriers make process of understanding during communication significantly complicated [4].

\section{Research Questions}

The question is raised about the possibility of communicative failures caused by communication barriers arising in the process of communication. Types of communicative barriers (avoidance, authority, misunderstanding), their characteristics and ways to overcome them are considered; besides, barriers related to difficulties or insufficient proficiency in a particular level of language (phonetic, lexical, stylistic) are considered. Among the reasons arising communicative barriers are: features of communicants' intelligence; difference in interpreting concepts; difference in vocabulary; lack of correct understanding of the situation of communication; psychological characteristics of partners; social, political, professional, religious differences.

\footnotetext{
*Corresponding author: new_life@mail.ru
} 


\section{Purpose of the Study}

The article deals with the types of communicative competence in different types of discourse. Communicative competence refers to the ability to predict a communicative situation in a specific area of communication, to participate and manage the process of communication in a certain situational environment.

\section{Research Methods}

The following methods have been used to conduct research: semantic analysis, discourse-analysis, method of cultural meanings' analysis. Levels of language personality formation are distinguished. The concept of a psychological barrier arising in the process of communication and impeding normal communication is given. Psychological barrier refers to a condition that impedes full development and manifestation of a personality. Multilevel character of communicative competence is revealed, levels of its formation are distinguished; such types as lexical, textual (genre) and discourse competence are considered. The dependence of the correct expression of emotions on the level of formation of communicative competence is distinguished.

\section{Findings}

We consider it possible to divide all communicative barriers into three groups: 1) language barriers insufficient knowledge of linguistic means (in particular, terminology), which are used in a certain sphere of discourse (medical, scientific, religious); 2) discourse barriers - lack of knowledge of norms and rules of communication in a certain communicative space within a certain discourse; 3) psychological barriers - barriers related to the will or emotional sphere of a person which can be explained by the insufficient development of a person's psychological readiness to enter and participate in the process of communication.

In general, five levels of linguistic personality formation can be distinguished: 1) level of correctness (assuming sufficient knowledge of lexical and structural units of the language which allow to build statements and texts in accordance with the rules of the language); 2) speed level (ability to perceive and produce utterances with natural speed); 3) level of saturation of vocabulary and language forms (in terms of the variety of linguistic expressive means use); 4) level of selection of the required language unit (from the point of view of the language means used, tonality which suits this sphere of communication and communicative situation, as well as necessary communicative role); 5) level of adequate synthesis (correspondence of the text produced by a person to the complex of informative and communicative tasks) [5].

Speaking about the peculiarities of discourse communication, it is necessary to consider the question of communicative competence. By communicative competence we mean the ability of a participant of communication to predict a situation in a particular sphere of communication as well as to participate in and manage the process of communication (both at a rational and emotional levels) in a certain situational environment.

The concept of communicative competence has a multi-level character, the following types of competence are distinguished:

1. Lexical competence: knowledge of lexical units and the main terms characteristic of this sphere of communication. Note, that in any type of discourse communication attention of the researcher is primarily concentrated on the meaningful side of the utterance. And only after that the researcher can turn to the form into which this content is enfolded. The shape, therefore, plays only the role of the outer shell, a "storage" for information. Form, therefore, doesn't matter on its own. Though, this statement is not relevant, for example, for the religious discourse. In religious discourse form is significant in itself, it has priority and in some cases it can be more important than the content [6]

2. Text (or genre) competence: the ability to navigate in the genre space of a particular discourse; understand and distinguish the main genre samples, as well as build certain genre fragments according to certain rules. Text competence presents the level of competence that follows lexical competence. After a communicant has elementary lexical base formed and begins to navigate in the main concepts and terms in a particular sphere of communication, he begins to form text or genre competence.

Text (genre) competence can be implemented in two types - passive and active. Formation of text competence begins at a passive level. Passive stage involves understanding of the main genres and the ability to distinguish (without any doubt, only at the level of an amateur, according to certain external characteristics) one genre from another. Following the passive level of text competence active level is formed, and it involves not only recognition and distinguishing the key genres but also the ability to build some of them. Active level of genre competence is a rather deep immersion in the communicative space of discourse. After the participant has entered this discourse rather deeply and acquired the necessary knowledge the text competence which was formed at the passive level passes to the active level, where the participant is able not only to distinguish the most important genres but, if necessary, to build certain genre fragments.

3. Discourse competence: represents the highest level of communicative competence; knowledge of language and ability to communicate in various spheres of discourse. Discourse, in a broad sense, is a text immersed in a situation of communication. Thus, discourse competence involves, besides language knowledge (this level of competence implies presence of all the above types of competence - lexical, text $/ g e n r e)$ the ability to navigate within the framework of this social institution.

Discourse competence is based on lexical competence, as well as text (genre) competence, which being built one on another like blocks create some basis 
for the further formation of a more complex and complicated discourse competence. Although some components that form this type of competence (for example, knowledge of some elements of ritual) are already formed in the early stages of a person's "entry" into a communicative space of a certain discourse.

To certain extent, it will be fair to say that discourse competence, having been formed in its full scale, really follows lexical and textual (genre) competence being the phenomenon of a higher level. However, it will not be an exaggeration to claim that some components of this competence are formed by a participant of communication at the very beginning of his entry into the communicative space of a certain discourse. However, it is possible to talk about complete and not fragmented formation of discourse competence only after a communicant has rather deeply immersed in the specific communicative field of this discourse. The development of discourse competence is a more complex, compared to the competence of the lexical and textual (genre) continuum.

In any type of discourse, a certain emotional message is hidden behind practically each word and each text. Emotions colour the text, give it additional meaning and sometimes change meaning of a message. In particular, even understanding itself begins at the level of emotions - at the beginning of any process of perception there is a corresponding reaction to the situation and emotional state of the partner, and only then meaning is decoded at the cognitive level [7].

Speaking about the process of communication, it should be noted that more often there are not words that are understood but what stands behind them - a communicative personality with its emotions [8]. Moreover, different emotional mood of communicants can lead to different accuracy of understanding, and in some cases to misunderstanding and impossibility to continue communication - the recipient perceives information passing it through his emotional field, his "emotional echo" may or may not meet the expectations of the addressee [9].

In the process of communication (as linguistics of emotions states), there is a change in the emotional field of the speech partner, "infection" with his emotions, a certain emotional interaction. At the same time, asymmetric emotions can be a subjective factor of the communicative barrier. E.V. Rudenskiy points out that there are some emotions that are negatively stable and thus create a communicative barrier, among them suffering, anger, aversion, fear, bad mood [10]. These emotions violate the level of communicative contact since negative emotional state of one communicant can be transmitted to his partner. Emotional interaction of partners is inevitable in the process of any communication.

Conducted analysis made it possible to conclude that as a person enters the discourse space and his communicative competence (active or passive) is being developed, there is inevitably a change in his emotional state - from negative or neutral emotions at the beginning of communication to positive emotions as the communicative competence of a person develops. As we move up the ladder of communicative competence the emotional background of the communicative personality radically changes. Even though the level of communicative competence and the emotional background, the mood of the communicative personality do not determine each other, their development and change go in parallel and it seems possible to establish several regularities in their co-relation. Each position, each level of communicative competence corresponds (to a greater extent) to a certain emotional mood of the participant in communication, which, on the one hand, is determined by general communicative practice and, accordingly, communicative competence of a person, and, on the other, depends to a certain degree on the level of formation of communicative and general discourse competence.

From a psychological point of view, three types (forms) of communicative barriers are distinguished: a) avoidance, b) authority, c) misunderstanding. This classification of barriers clearly shows that communication barrier is in many ways a mechanism for protecting against unwanted information.

Psychological barrier that the recipient puts on the way of unwanted, tedious, or dangerous information may have various degrees of transparency [11]. An opaque barrier is avoidance. Unwanted information can be avoided both physically (avoiding communication) and psychologically (ignoring information). Psychological barriers are among the most frequent and common ones. Such barriers are characteristic of communication in the framework of scientific, religious, and medical discourse [12].

The second barrier is authority, action of which can be interpreted as follows: information enters consciousness, but on its way, it is significantly depreciated through a subjective decrease in the authority of its source - that is, in the end, it becomes unreliable and insignificant. Such barriers arise in everyday communication when communicants have equal status [13]. In this case, the addressee may decide that this information is not interesting for him or not relevant, and unilaterally he may "refuse" it and leave communication without any "sanctions".

The third barrier is misunderstanding. The reasons for communication barriers can be found in the content and formal characteristics of the message itself, as well as in the logic of its construction. Logical barrier occurs when partners cannot find a common language. Each person sees the world, the situation, the problem that is discussed, from his point of view, which may not coincide with the position of the partner. In addition, the same words in a particular situation may have a completely different meaning, which is always individual-personal: it arises in the consciousness of the one who speaks, but is not necessarily understandable to the one who listens.

From a linguistic point of view, barriers can be phonetic, semantic (lexical), structural (incorrect division of the heard phrase).

Phonetic barriers (obstacles that are created by the peculiarities of the speaker's language) usually arise when participants in the process of communication speak 
different languages, dialects, have defects of speech and diction, distorted grammatical construction of statements.

Psychologists have also proved that when something is reported to a person in elevated tones, understanding is often blocked. Psychologically, the reason lies in the fact that all attention of the individual in this case is aimed at the flow of offensive words and the intonation pattern of the phrase. As a result, a protective reaction occurs and we can observe a shift of attention.

Semantic barrier often arises due to the absence of matches in the value systems of communication partners (thesaurus). Semantic barrier is, firstly, a problem in jargon and slang; secondly, in the limited vocabulary of one of the interlocutors; thirdly, social, cultural, psychological, national, religious, professional, group and other features of communication.

T. Dridze considers communicative situations in which this effect arises: a. clear discrepancy between the language means used by the communicator and the language resources of the recipient; $b$. discrepancy arises even earlier - at the stage of conversion thought into words; c. mutual understanding can be hampered by certain individual characteristics of the recipient - ability to operate with language as a means of thinking [14].

Stylistic barrier arises when style of speech of the communicant, situation of communication and actual psychological state of the recipient do not correspond. For example, a communicant may not accept critical remark of the interlocutor, because it is said in a friendly manner. A stylistic barrier can also arise provided that the form and content of communication do not correspond. A stylistic barrier also occurs when information is transmitted in a style that is not characteristic of this area of communication.

Let us list the most general reasons for communication barriers: a. peculiarities of communicant's intelligence; b. different understanding (interpretation) of the subject of the conversation; $c$. different vocabulary (lexicon, thesaurus); d. absence of a common understanding of the situation of communication; e. certain psychological features of partners; f. social, political, professional, religious differences [15].

Barriers associated with the communicative characteristics of participants are social or psychological in nature.

In the process of communication, it is important not just to transmit information, but to be able to manage the "direction" of thinking of the partner of communication. The effectiveness of communication depends significantly on how deeply partners are involved in the process of communication.

\section{Conclusion}

To overcome communication barriers, the addressee must possess the art of "managing the partner's attention". Research in the field of psychology has shown that attention can be attracted by external and internal factors. External include novelty (unpredictability) of the message, intensity, and physical characteristics of the signal; to internal - relevance, significance, importance of information for a person.

To increase the effectiveness of communication, it is important to be able to direct thinking of communicative partner to the "right" direction. To be understood by the interlocutor, you need to take into account logic of the partner. To do this, you need to take a partner's position, to understand his individual and socio-role characteristics. Understanding the partner, adequate interpretation of his point of view, goals, individual features are the main conditions for overcoming psychological barriers arising in the process of discourse communication.

\section{References}

1. V.I. Karasik, Language manifestation of the personality. (Volgograd: Paradigma, 2014)

2. E.V. Bobyreva, M.R. Zheltukhina, O.A. Dmitrieva, \& M.V. Busygina, Advances in Social Science Education and Humanities Research 97, 52-56 (2017)

3. A. A. Ivin, Axiology. (M.: Yurait, 2018).

4. G.I. Goddess, Model of linguistic personality in its relation to varieties of the text: diss... doct. philol. sciences (Leningrad, 1984).

5. E.K. Chernichkina, Artificial bilingualism: linguistic status and characteristics: autoref. dis. ... doct. philol. sciences (Volgograd: Peremena, 2007).

6. O.F. Khudobina, Pedagogical conditions for overcoming psychological barriers by students in the process of bilingual education at a university: autoref, diss... kand. pedagogical. sciences (Volgograd: Peremena, 2007).

7. S.E. Krivykh, Axiology of world religions: a comparative typology of value structures: dis. ...cand. phil. Sciences. (Armavir, 2009)

8. E.V. Bobyreva, M.R., Zheltukhina, K.G Korovina,. \& M.V. Busygina, SHS Web Conf, 69, 00021 (2019).

9. V. I. Shakhovskiy, Linguistic theory of emotions (Moscow: Gnozis, 2008)

10. E.V. Rudenskiy Conceptual foundations of psychology of an adapting personality: an introduction to the psychological theory of the social functioning of the personality (Novosibirsk: Institute of Personality Psychology, 1997)

11. E. I. Melibruda, I - You - We: psychological opportunities for improving communication (M.: Progress, 1986)

12. D.Z. Akhmetova, T.S. Artyukhina, M.R. Bikbaeva, I. A. Sakhnova, M.A. Suchkov, \& E.A. Zaitseva, Higher education in Russia, 29(2), 141-150 (2019)

13. E. A. Akhverdiev, \& A. V. Ponomarev, International Scientific and Practical Conference "Current Issues of Linguistics and Didactics: The Interdisciplinary Approach in Humanities and Social Sciences": SHS Web Conf., 50. (2018)

14. T.M. Dridze, Next activity in the structure of social communication (Moscow: Nauka, 1984).

15. E.P. Panova, \& N.R Saenko, Service plus, 94-102 (2020) 